九州大学学術情報リポジトリ

Kyushu University Institutional Repository

Taxonomic Study of the Genus Augustinus Korotyaev from Japan (Coleoptera: Curculionidae: Ceutorhynchinae)

Yoshitake, Hiraku

Entomological Laboratory, Graduate School of Bioresource and Bioenvironmental Sciences, Kyushu University

https://doi.org/10.5109/2706

出版情報: ESAKIA. 45，pp.155-178，2005-03-31. Entomological Laboratory，Faculty of Agriculture, Kyushu University バージョン：

権利関係 : 
ESAKIA, (45): 155-178. March 31, 2005

\title{
Taxonomic Study of the Genus Augustinus Korotyaev from Japan (Coleoptera: Curculionidae: Ceutorhynchinae)*
}

\author{
Hiraku YOSHITAKE \\ Entomological Laboratory, Graduate School of Bioresource and Bioenvironmental Sciences, \\ Kyushu University, Fukuoka, 812-8581 Japan
}

\begin{abstract}
A new species of the genus Augustinus Korotyaev, 1981 (Cnemogonini, Ceutorhynchinae) is described. Five Japanese species including the new species are studied taxonomically and classified into the following three species groups: the longipes-group contains Augustinus longipes (Korotyaev, 1981) and $A$. comes sp. nov., and is characterized mainly by the sinuate and edentate mid femora, a median expansion on the internal margins of the mid and hind tibiae, and the ventrally prominent metasternal receptacle; the bouvierigroup consisting of Augustinus bouvieri (Hustache, 1916) and A. similis (Chûj $\hat{o}, 1959)$ is similar to the longipes-group in having the robust rostrum with a median slit and the smooth prominences on the pronotum, but differs from it in having the clavate and dentate mid femora, the smooth internal margins of the mid and hind tibiae, and the flat metasternum; the sasakii-group consists of $A$. sasakii (Chûjô, 1959) and is clearly different from the other two groups in possessing the slenderer rostrum with a median ridge and the denticulate prominences on the pronotum. A key to the Japanese species is provided, in addition to habitus photographs and line drawings of important features for each species with the exception of $A$. sasakii, as well as biological notes on the three species that are associated with Leucosceptrum (Lamiaceae).
\end{abstract}

Key words: Taxonomy, Coleoptera, Curculionidae, Ceutorhynchinae, Cnemogonini, Augustinus, species group, new species, host plant.

\section{Introduction}

The genus Augustinus Korotyaev was first established as a subgenus of the genus

* Contribution from the Entomological Laboratory, Faculty of Agriculture, Kyushu University, Fukuoka (Ser. 6, No. 14). 
Cyphosenus in the tribe Egriini Pajni \& Kohli, 1982 of the subfamily Ceutorhynchinae. Soon after this classification, Colonnelli (1982) raised Augustinus to a full genus and transferred it from the tribe Egriini to Cnemogonini Colonnelli, 1979 of the same subfamily. This genus is characterized mainly by the black and thinly squamate body, a pair of large prominences on the pronotum, and the presence of denticulate tubercles and acute granules on odd-numbered intervals of the elytra.

Augustinus at present contains four species from Japan and seven from Vietnam (Colonnelli, 2004). The species Augustinus longipes (Korotyaev, 1981), A. bouvieri (Hustache, 1916), A. sasakii (Chûjô, 1959), and A. similis (Chûjô, 1959) have been recorded in Japan. However, they are extremely difficult to identify due to close similarities in general appearance and the lack of detailed taxonomic studies. Biological information on Augustinus weevils is extremely limited and their host plants have not yet been confirmed, though adults of Augustinus similis are known to feed on Leucosceptrum japonicum (Miquel) Kitamura et Murata forma barbinerve (Miquel) Kitamura et Murata, a herbaceous plant of the family Lamiaceae.

This paper aims to revise the Japanese species of Augustinus, including a description of a new species from West Japan and redescriptions of all known Japanese species with the exception of Augustinus sasakii (Chûjô, 1959), which is not available and only referenced from the literature owing to missing type specimens. Descriptions of species are complemented with detailed figures of the male and female genitalia for the first time for species of this genus. Additionally, biological and distributional information is provided to assist future phylogenetic and biogeographical studies of Augustinus. Finally, an attempt is made to subdivide the Japanese species into groups with shared morphological features as the first step in developing intrageneric classification system of Augustinus species.

\section{Materials and Methods}

This study was based on the examination of specimens from the following institutions and private collections. AY: A. Yoshida collection, Inagi; ELEU: Entomological Laboratory, College of Agriculture, Ehime University, Matsuyama; ELKU: Entomological Laboratory, Faculty of Agriculture, Kyushu University, Fukuoka; HI: H. Ichihashi collection, Komono; HUM: Hokkaido University Museum, Sapporo; HY: H. Yoshitake collection, ELKU, Fukuoka; IM: I. Matoba collection, Wakayama Prefecture Museum of Natural History, Kainan; KUM: Kyushu University Museum, Fukuoka; MNHN: Muséum National d'Histoire Naturelle, Paris; SS: S. Saitou collection, Fukushima; TN: T. Nohira collection, Kagamihara; YN: Y. Notsu collection, Hiratsuka; YS: Y. Shiozaki collection, Kawasaki. Methods used in this study for descriptions are identical to those outlined in Yoshitake \& Yamauchi (2002). The holotype of the new species is preserved in ELKU. 
Biological information was obtained through personal communications with Dr. Y. Sawada (Koube), Mr. M. Horikawa (Yokohama), Mr. H. Hirano (ELKU), and Mr. H. Ichihashi (Komono). The distribution range of each species was determined principally on the localities of specimens examined, with additional data incorporated from the studies of Chûjô (1959) and Korotyaev (1981).

\section{Taxonomy}

\section{Genus Augustinus Korotyaev, 1981}

Cyphosenus (Augustinus) Korotyaev, 1981, 130 (type species: Cyphosenus (Augustinus) longipes Korotyaev, 1981; Egriini).

Augustinus: Colonnelli, 1982, 4 (Cnemogonini). - Alonso-Zarazaga \& Lyal, 1999, 106

(Cnemogonini, in world catalog of Curculionoidea). - Colonnelli, 2004, 74

(Cnemogonini, in world catalog of Ceutorhynchinae). - Yoshitake et al., 2004, 103

(Cnemogonini, in checklist of Japanese weevils).

Diagnosis. This genus is considered to have certain relation to Cyphauleutes Korotyaev, 1992 (Yoshitake, unpubl.) in having the robust and apically strongly dilated rostrum (Figs. 1,2), the smooth basal margin of the pronotum (Fig. 4), no jumping organ in the hind legs (Fig. 10), and the abrupt posterior wall of the deep sternal canal (Figs. 5, 7), in addition to the similarity in the body shape. However, Augustinus is readily distinguished from Cyphauleutes by the pitchy black body with sparse vestiture and without scaly tufts (Figs. 4, 6,8 ), the absence of paired lateral tubercles on pronotum (Figs. 4,5 ), the long vibrissae fringing ocular lobes (Figs. 5, 6), and the denticulate tubercles and sharp granules in various size on odd-numbered intervals of elytra (Fig. 8).

Redescription. Male. Black in general appearance; antennae reddish brown; legs tinged with red. Integument more or less shining, evenly covered with ochreous powder in life.

Head moderately clothed with light-colored narrow scales; each scale truncate or rounded at apex. Rostrum covered with scales as those on head in basal half, then with paler long hairlike scales to apex. Prothorax moderately clothed with light brown narrow scales, mingled with white ones; dorsum with darker scales in middle; basal margin, fringed with a row of feather-like scales, lacking hairs (Fig. 4); ocular lobes fringed with long vibrissae (Figs. 5, 6). Elytra sparsely clothed with light brown narrow and darker linear scales; scales more conspicuous on tubercles and granules; interval I with a postscutellar patch of velvety scales; patch often obscure or diminished. Legs moderately covered with white narrow scales, mingled with brown ones; scales replaced with yellowish hairs in apical part of each tibia. Lateral pieces of meso- and metasterna sparsely with light and dark brown narrow scales and with 


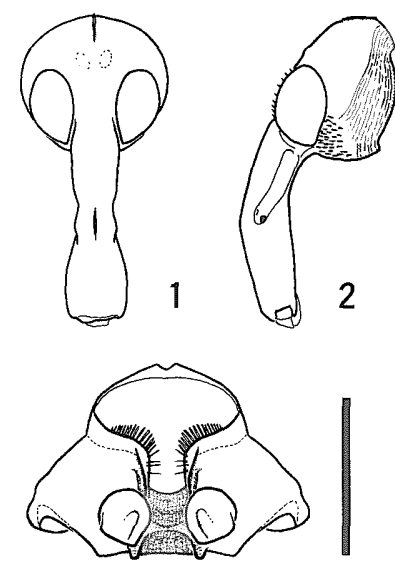

5

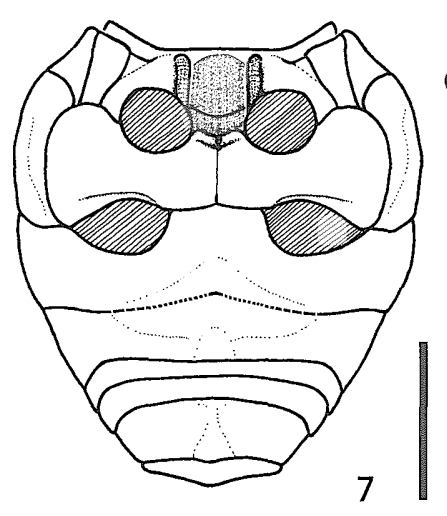

7
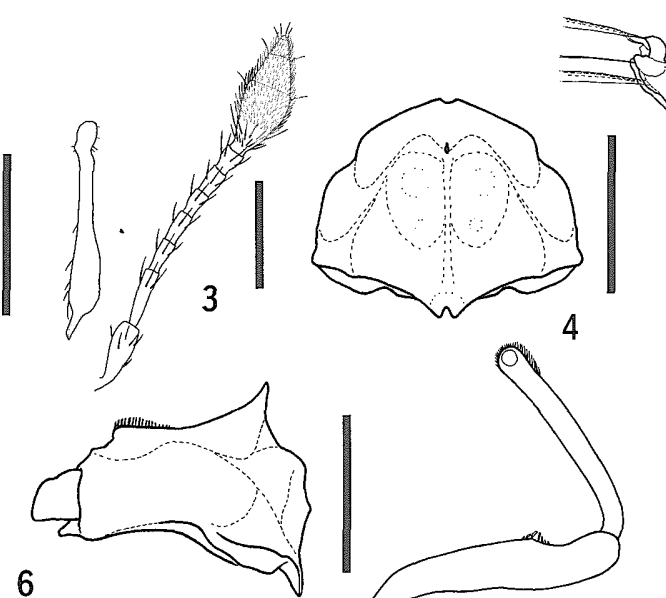

6

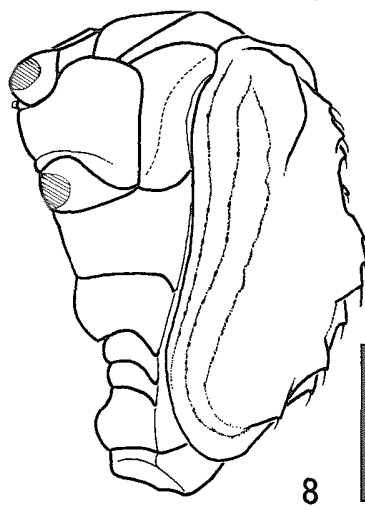

8

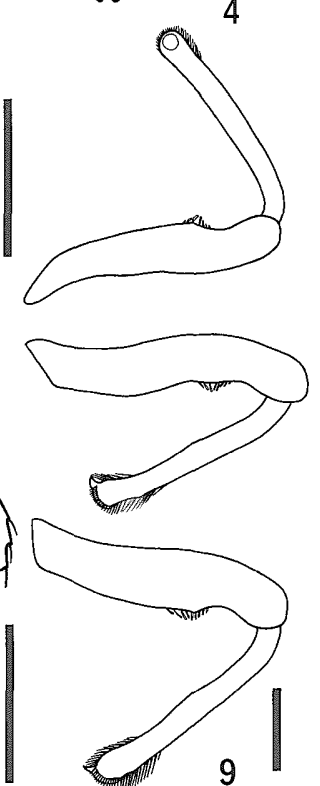

9
10
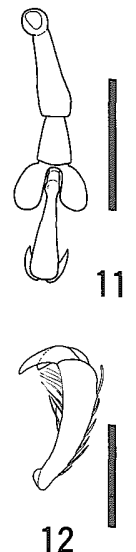

12

Figs. 1-12. Diagnostic characteristics of Augustinus (A. longipes, male). - 1, Head, dorsal view; 2 , ditto, lateral view; 3 , antenna; 4, prothorax, dorsal view; 5 , ditto, ventral view; 6 , ditto, lateral view; 7, pterothorax and abdomen, ventral view; 8, ditto, lateral view; 9, legs; 10 , hind tibia, showing extensor and flexor tendons; 11 , tarsus; 12 , tarsomere V, lateral view. Scale: $1.00 \mathrm{~mm}$ for $1,2,4-8 ; 0.50 \mathrm{~mm}$ for $9-11 ; 0.25 \mathrm{~mm}$ for 3,12 .

white lanceolate scales on periphery. Underside moderately with velvety gray oval to lanceolate scales and sparsely with minute linear ones on sides; ventrites III and IV nearly naked; ventrite $\mathrm{V}$ rather densely covered with lanceolate scales on disc. Pygidium clothed with dark hair-like scales.

Head (Figs. 1, 2) densely punctured, with a pair of smooth spots in middle; forehead depressed, slightly narrower than base of rostrum. Eyes (Figs. 1, 2) moderately or strongly prominent from outline of head, not or slightly approximated anteriorly. Rostrum (Figs. 1, 2) more or less robust, nearly as long as prothorax, abruptly curved in apical half; dorsum coarsely and reticulately punctured, with a slit in median area between antennal insertions or 
carinate along midline in basal part; sides subparallel from base to antennal insertion, then more or less expanded apically; antennal scrobes well-separated in entire length. Antennae (Fig. 3) inserted at or just behind middle of rostrum; scape nearly as long as funicular segments I, II, and III combined, vertically produced into a long lamina at apex; funicle 7segmented, with segment I as long as II, II slender, twice as long as III, III as long as IV, IV slightly longer than V, V as long as VI, VI slightly longer and narrower than VII, and VII as long as wide; club lanceolate, finely pubescent except basal $1 / 3$.

Prothorax (Figs. 4-6) slightly wider than long, widest at base, subparallel-sided from base to apical $1 / 3$, then rapidly convergent toward strong subapical constriction; dorsum densely punctured, with a pair of large and smooth prominences in middle; each prominence with a glabrous spot on its outer surface, often 2-peaked or rugged; apical margin produced into an obtuse angle and minutely notched in middle; basal margin simple, not serrate.

Elytra (Fig. 8) cordate, slightly wider than or as wide as long, widest just behind humeri, slightly narrowed to middle, then rapidly convergent toward rugged subapical calli; suture evidently bent leftwards; interval I of left elytron narrower than that of right elytron; oddnumbered intervals wider than even-numbered ones, bearing more or less strong tubercles and large granules; tubercles and granules acute, each bearing 1-6 dark hair-like scales in various size; striae sinuate, shallow but well-marked, shining, with a row of minute hair-like scales in middle; each puncture in striae elliptic, separated by distance more than its diameter. Hind wings as in Fig. 13.

Legs (Figs. 9-12) slender, lacking jumping organ; tibiae fringed with slender setae apically and mucronate at apex except fore legs; tarsi simple, without projection; claws without seta, appendiculate with a large tooth.

Sterna sparsely punctured; metasternum densely punctured on disc. Sternal canal (Figs. 5, 7) very deep, extending to anterior part of metasternum; mesosternal canal ridged laterally in entire length; ridges slightly projected over metasternum; metasternal canal terminated in abrupt wall and V-shaped margin. Metendosternite as in Fig. 17. Venter (Fig. 7) moderately punctured; punctures becoming sparser toward sides; ventrites I and II with shallow, cruciform concavity in middle; concavity devoid of punctures in center; ventrites III and IV devoid of punctures on disc; ventrite $\mathrm{V}$ with a more or less deep semicircular concavity on disc. Terga as in Figs. 14-16; tergite VII with a pair of minute plectral tubercles; tergite VIII transversepentagonal, finely punctured, shining, carinate in middle; upper flange smooth, without projection.

Female. Rostrum as long as or slightly longer than that of male, more gently curved, sparsely clothed with fine hair-like scales on apical $2 / 3$. Antennae inserted behind middle of rostrum. All tibiae simple, not mucronate at apex. Ventrites I and II more or less inflated. Pygidium smaller, flattened or slightly depressed. Sternite VIII (Figs. 44, 47, 73, 76) furnished with more or less short setae at apex; arms shorter than coxite and stylus combined; 

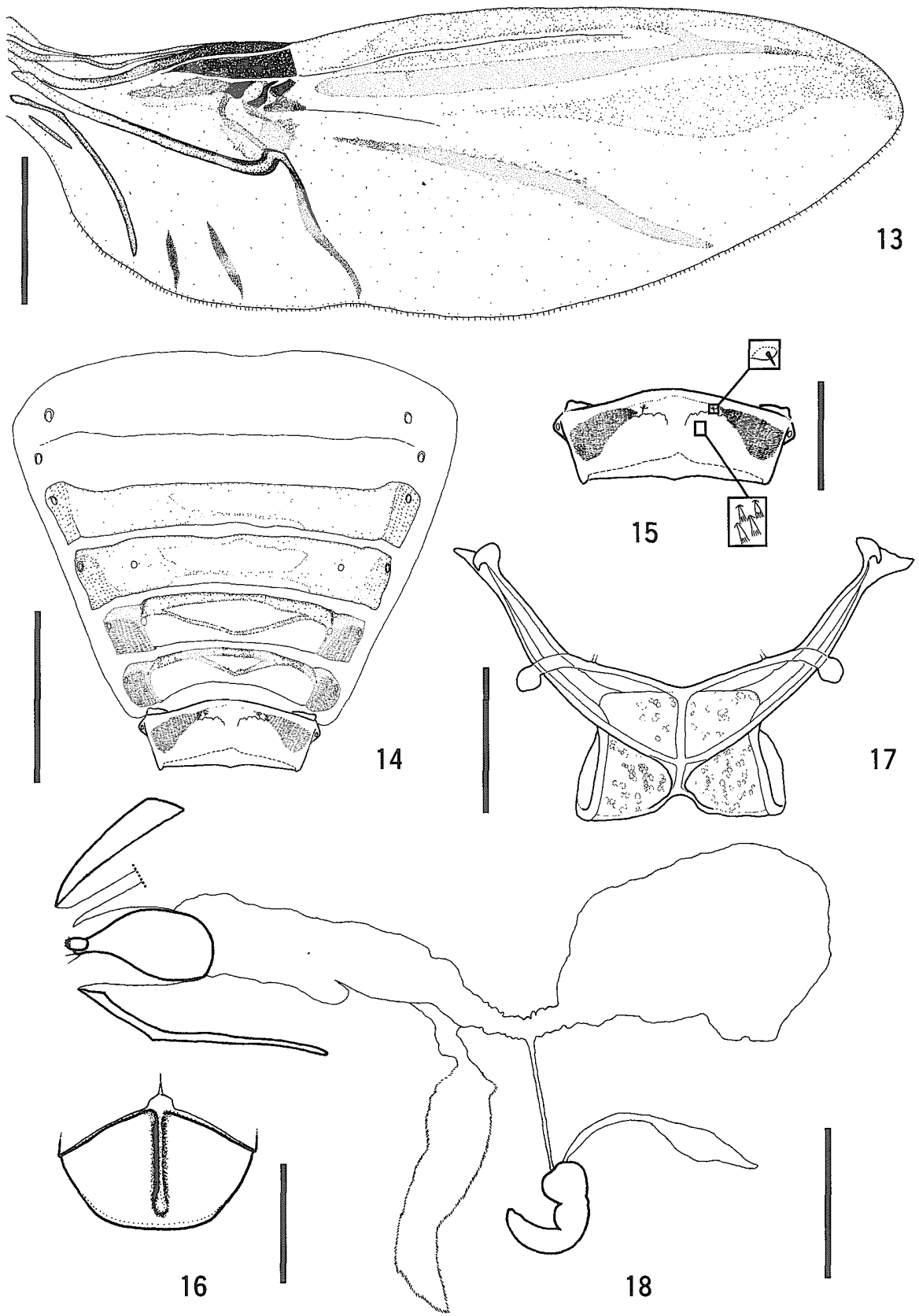

Figs. 13-18. Diagnostic characteristics of Augustinus (13-17, A. longipes, male; 18, ditto, female) . -13 , Hind wing; 14, tergites, except tergite VIII; 15, tergite VII, enlarged; 16, tergite VIII; 17, metendosternite; 18 , female genitalia. Scale: $1.00 \mathrm{~mm}$ for $13 ; 0.50 \mathrm{~mm}$ for $14,16-18 ; 0.25 \mathrm{~mm}$ for 15 . 
apodemes relatively short. Ovipositor (Figs. 18, 45, 48, 74, 77) with coxites large and robust, longer than body of sternite VIII, well-sclerotized, furnished with several slender setae at apex; styli apicolaterally inserted, furnished with several minute setae apically. Spermatheca (Figs. 46, 49, 75, 78) with ramus moderately developed; insertions of duct and gland close to each other. Otherwise practically as in male.

Distribution. Japan, Vietnam.

Comments. Colonnelli $(1982,2004)$ placed Augustinus in the tribe Cnemogonini, but its systematic position is still uncertain owing to the lack of molecular and detailed morphological studies of Ceutorhynchinae. In this study, I followed Colonnelli's placement of this genus for convenience.

\section{Augustinus longipes Korotyaev, 1981}

Cyphosenus (Augustinus) longipes Korotyaev, 1981, 134 (type locality: Japan). -Morimoto, 1989, 514 (in checklist).

Augustinus longipes: Colonnelli, 1982, 4; 2004, 74 (in catalog). _-Yoshitake et al., 2004, 103 (in checklist).

Diagnosis. Augustinus longipes is very similar to A. comes sp. nov., but the prothorax is wider, the fore tibiae lacks apical outer dilation, the ventrite I shows sparser punctures in the middle, the male aedeagus (Fig. 27) has sinuate sides, the female rostrum is slightly longer than prothorax, and the ventrite $\mathrm{V}$ bears hair- and feather-like scales in a shallower median concavity.

Redescription. Male. Length of body: 3.13-3.67 mm. Length of rostrum: 1.10-1.27 mm. Maximum width of pronotum: 1.40-1.50 mm. Length of pronotum: 1.13-1.30 mm. Maximum width of elytra: $2.37-2.77 \mathrm{~mm}$. Length of elytra: $2.27-2.70 \mathrm{~mm} . \mathrm{N}=3$, for all measurements. Habitus as shown in Figs. 23, 24.

Forehead weakly depressed. Eyes moderately prominent upwards, not approximated anteriorly. Rostrum (Figs. 1, 2) robust; dorsum with a short slit in median area between antennal insertions; sides rather strongly expanded apicad. Rostrum 0.97-1.00 times as long as prothorax, not carinate. Prothorax 1.15-1.24 times as wide as long, clothed with narrow scales; discal prominences smooth, often obtusely 2-peaked. Elytra 0.96-0.99 times as long as wide, lacking conspicuous scaly maculation. Mid femora sinuate and edentate (Fig. 19). Fore and hind femora faintly toothed (Fig. 9). Fore tibiae simple, not dilated outwards at apex. Mid and hind tibiae (Figs. 9, 19) bisinuate along inner margins. Metasternum (Fig. 20) prominent ventrally along posterior margin of metasternal canal, minutely projected at middle of its anterior margin (Fig. 20). Ventrite I moderately punctured in middle. Spiculum gastrale (Fig. 33) much shorter than aedeagal body and its apodeme taken together, strongly 

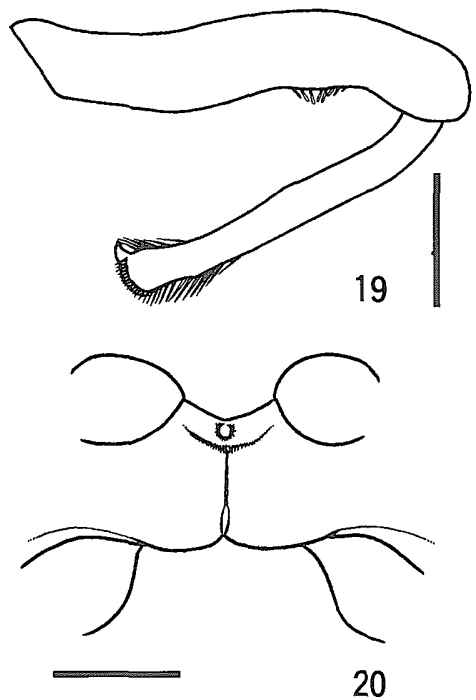
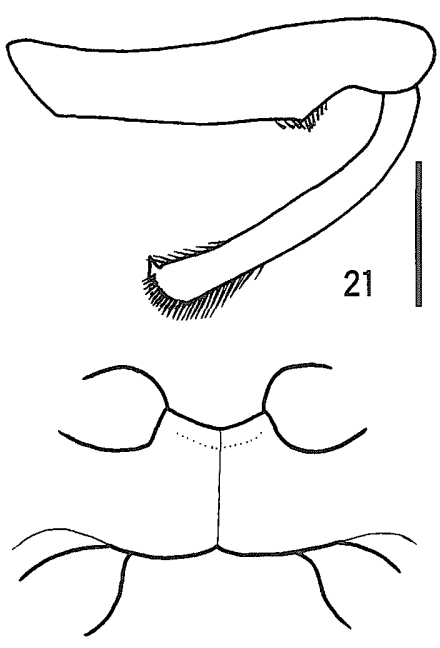

22

Figs. 19-22. Diagnostic characteristics of the longipes- and bouvieri-groups (19, 20, A. longies, male; 21,22 , A. bouvieri, male). - 19, 21, Legs; 20, 22, metasternal receptacles. Scale: $0.50 \mathrm{~mm}$.

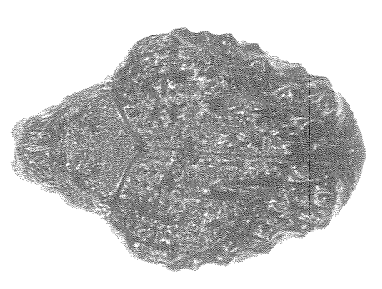

23

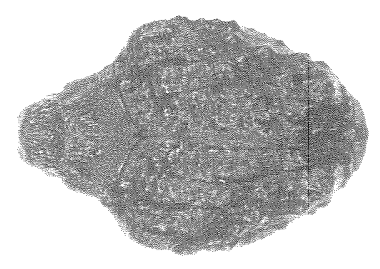

25

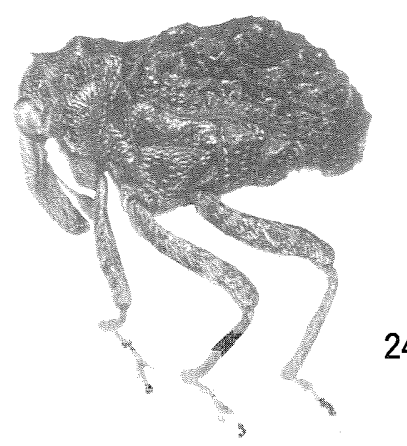

24

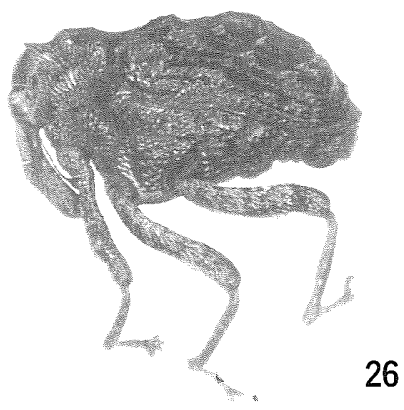

Figs. 23-26. Habitus of Augustinus spp. (the longipes-group). -23, 24, A. longipes, male; 25, 26, A. comes, male. 
curved leftwards. Tegmen (Fig. 34) with an apodeme shorter than diameter of tegminal ring. Aedeagal body (Figs. 27-29) robust, moderately curved; apical projection minute; sides slightly sinuate, with 2 small notches near base; apodeme slender, 1.30 times as long as body. Endophallus (Fig. 27) short, nearly as long as aedeagal body and its apodeme taken together, with a pair of slender plate-like sclerites at base, a pair of complex sclerites in middle, and ca. 20 black dentiform sclerites (Figs. 30-32) in apical part, of which basal 4 larger and tridenticulate (Fig. 30), often mingled with bidenticulate ones (Fig. 31), and apical 15-16 smaller and monodenticulate.

Female. Length of body: 3.53-3.97 mm. Length of rostrum: $1.33-1.53 \mathrm{~mm}$. Maximum width of pronotum: 1.47-1.63 mm. Length of pronotum: 1.27-1.40 mm. Maximum width of elytra: 2.67-3.00 mm. Length of elytra: $2.53-2.90 \mathrm{~mm}$. $\mathrm{N}=4$, for all measurements.

Rostrum slenderer, 1.05-1.13 times as long as prothorax. Prothorax 1.15-1.26 times as wide as long. Elytra 0.97-0.99 times as long as wide. Metasternum simple, not projected at middle of its anterior margin. Concavity on ventrites I and II indistinct. Concavity on ventrite V shallower, sparsely with hair- and feather-like scales. Sternites VIII (Fig. 44) very wide; arms nearly half as long as apodemes, distantly separated. Ovipositor (Fig. 45) with coxites nearly 5.0 times as long as styli; styli cylindrical, nearly 1.50 times as long as broad. Spermatheca (Fig. 46) with cornu relatively short; collum moderately convex; gland short, at most twice as long as body.

Specimens examined. JAPAN: KYUSHU. 1 male, Mt. Shiratori, Izumi, Kumamoto, 18. v. 1997, N. Touru (ELKU). 1 male, Naidaijin-rindou, Yabe-machi, Kumamoto, 21. v. 1998, H. Kojima (ELKU) . 1 female, Shiiya-touge, Kumamoto-Miyazaki, 25. v. 1974, I. Ohtsuka (ELKU). 1 male, Mt. Hiko, Fukuoka, 17-19 v. 1967, H. Takizawa (HY). 2 females, Mt. Kuju, Oita, 13-15. v. 1967, H. Takizawa (HY). 1 female, Mt. Raizan, Fukuoka, 3. ix. 1996, S. Miyamoto (ELKU). 2 males, Mt. Sefuri, Saga-Fukuoka, 17. v. 2003, S. Mansai (HY). 1 female, Mt. Shibisan, Miyanojou, Kagoshima, 22. xii. 1991, S. Nomura (ELKU).

Distribution. Japan: Kyushu (Fig. 79).

Augustinus comes sp. nov.

Diagnosis. This species is very similar to A. longipes (Korotyaev), but is different in the slightly shorter rostrum than prothorax in both sexes, the narrower prothorax, the male ventrite I with denser punctation in median part, the female ventrite $\mathrm{V}$ only with hair-like scales on a median concavity, and the male aedeagal body (Fig. 35) with straight sides.

Description. Male. Length of body: $3.73 \mathrm{~mm}$. Length of rostrum: $1.33 \mathrm{~mm}$. Maximum width of pronotum: $1.50 \mathrm{~mm}$. Length of pronotum: $1.36 \mathrm{~mm}$. Maximum width of elytra: 2.83 mm. Length of elytra: $2.73 \mathrm{~mm}$. $\mathrm{N}=1$, for all measurements. Habitus as shown in Figs. 25, 26. 

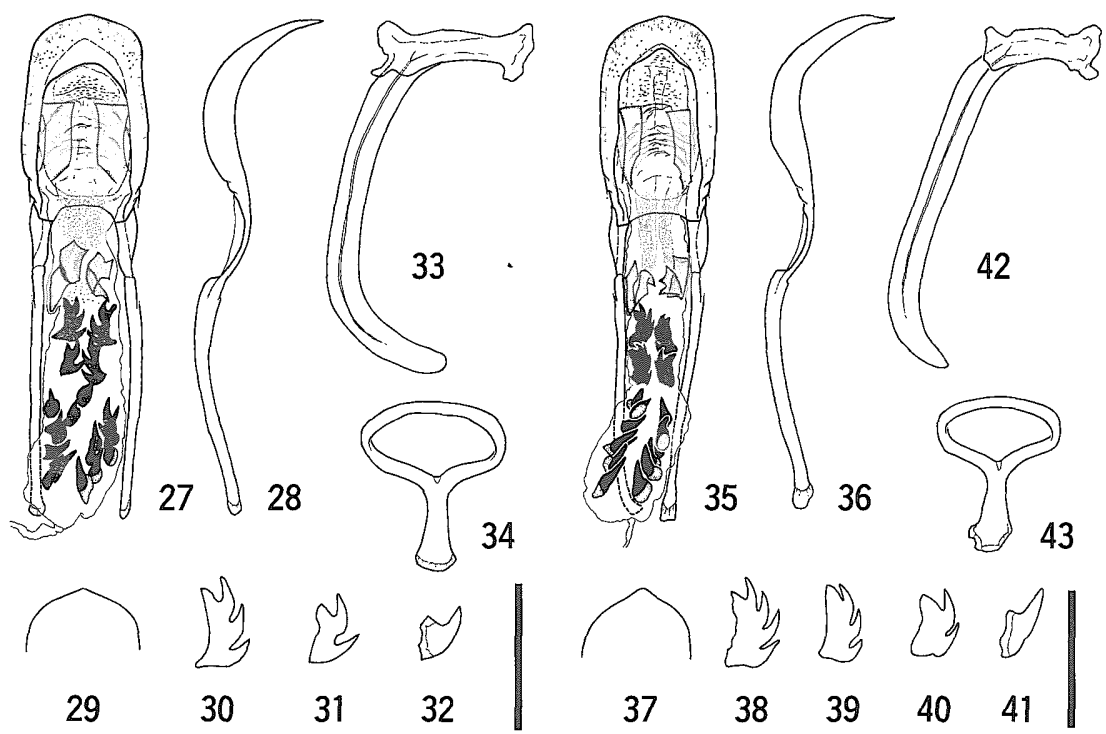

Figs. 27-43. Male genitalia of Augustinus spp. (the longipes-group). -27-34, A. longipes; 35-43. A. comes; 27, 35, aedeagus, dorsal view, showing endophallic structures; 28,36 , ditto, lateral view; 29,37 , apex of aedeagal body; 30-32, 38-41, endophallic sclerites, enlarged; 33, 42, sternite IX; 34, 43, tegmen. Scale: $0.50 \mathrm{~mm}$, except for 30-32, 38-41.

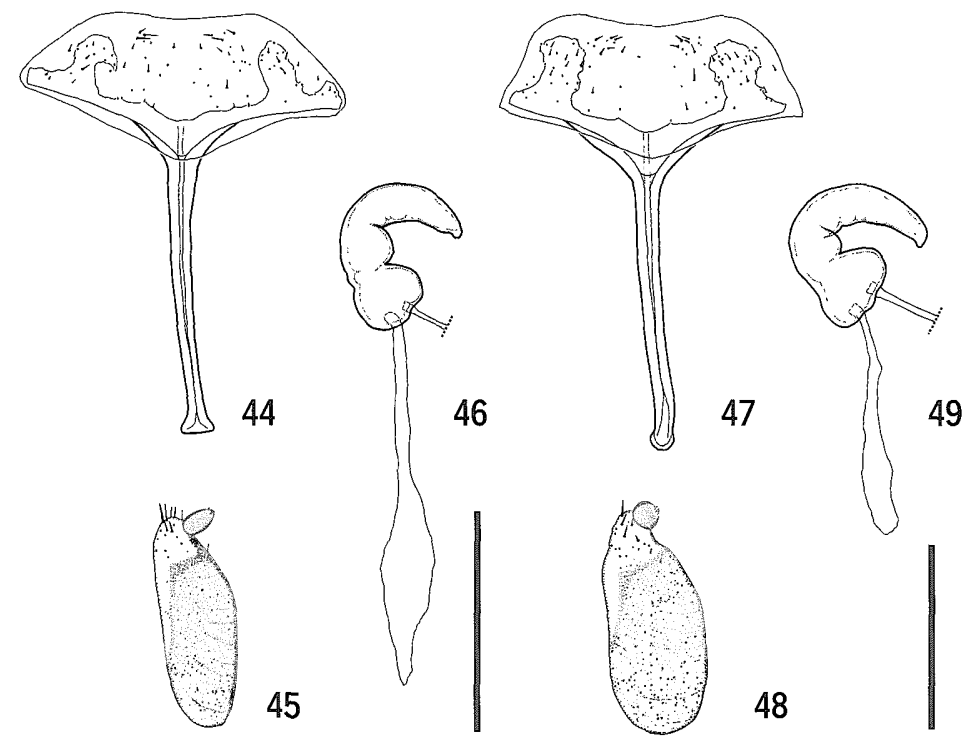

Figs. 44-49. Female genitalia of Augustinus spp. (the longipes-group). - 44-46, A. longipes; 47-49. A. comes; 44, 47, sternite VIII; 45, 48, ovipositor; 46, 49, spermatheca. Scale: $0.50 \mathrm{~mm}$. 
Rostrum 0.98 times as long as prothorax. Prothorax narrower, 1.10 times as wide as long, clothed with fine scales. Elytra 0.96 times as long as wide. Fore tibiae slightly dilated outwards in apical parts. Ventrite I rather densely punctured in middle. Spiculum gastrale (Fig. 42) much shorter than aedeagal body and its apodeme taken together, moderately curved leftwards. Tegmen (Fig. 43) with an apodeme shorter than diameter of tegminal ring. Aedeagal body (Figs. 35-37) robust, strongly curved; sides straight; apical projection well-developed; apodeme slender, 1.30 times as long as aedeagal body. Endophallus (Fig. 35) short, nearly as long as aedeagal body and its apodeme taken together, with a pair of slender plate-like sclerites at base, with a pair of complex sclerites in middle, and with ca. 20 black dentiform sclerites in apical part, of which basal 4 larger and tridenticulate (Fig. 39), often mingled with bi- and quadridenticulate ones (Figs. 38, 40), and apical 14-16 smaller and monodenticulate (Fig. 41). Otherwise practically as in A. longipes.

Female. Length of body: $3.60 \mathrm{~mm}$. Length of rostrum: $1.30 \mathrm{~mm}$. Maximum width of pronotum: $1.57 \mathrm{~mm}$. Length of pronotum: $1.33 \mathrm{~mm}$. Maximum width of elytra: $2.73 \mathrm{~mm}$. Length of elytra: $2.60 \mathrm{~mm}$. $\mathrm{N}=1$, for all measurements.

Rostrum shorter, 0.98 times as long as prothorax. Prothorax 1.18 times as wide as long. Elytra 0.95 times as long as wide. Concavity on ventrite V deeper, sparsely with hair-like scales. Sternite VIII (Fig. 47) with arms nearly half as long as apodemes. Ovipositor (Fig. 48) with coxites nearly 7.0 times as long as styli; styli spherical, nearly as long as wide. Spermatheca (Fig. 49) with cornu longer; collum strongly and obliquely convex upwards; gland shorter.

Type material. Holotype male (Type No. 3183, ELKU), Sakanotani, Mt. Hyounosen, Tottori, Honshu, Japan, 28. v. 2002, Y. Sawada (ELKU). Paratypes. JAPAN: HONSHU. 3 males, Mt. Hyounosen, Tottori, 7. vi. 1987, K. Yoshihara (KUM). 1 female, Mt. Takahachi, Saji, Tottori, 9. vi. 1985, A. Watanabe (YS). 1 female, Fudagatao, Takano, Hiroshima, 26. vii. 1995, S. Nakamura (ELKU).

Distribution. Japan: West Honshu (Fig. 79).

Biological notes. According to Y. Sawada, (pers. comm., 2002), in the type locality (Fig. 50 ), the adults of this species were observed feeding on the leaves of Leucosceptrum japonicum (Miquel) Kitamura et Murata (Lamiaceae) (Fig. 51), which was growing gregariously along the edge of a forest, and leaving circular feeding traces, 2.00-5.00 $\mathrm{mm}$ in diameter (Fig. 52). A female laid 1-3 eggs into basal part of the midrib on the underside of a leaf and concealed oviposition scars by excreta or a kind of secretion (Figs. 53, 54).

Etymology. The species name is a Latin meaning companion, after its close affinity with A. longipes. 


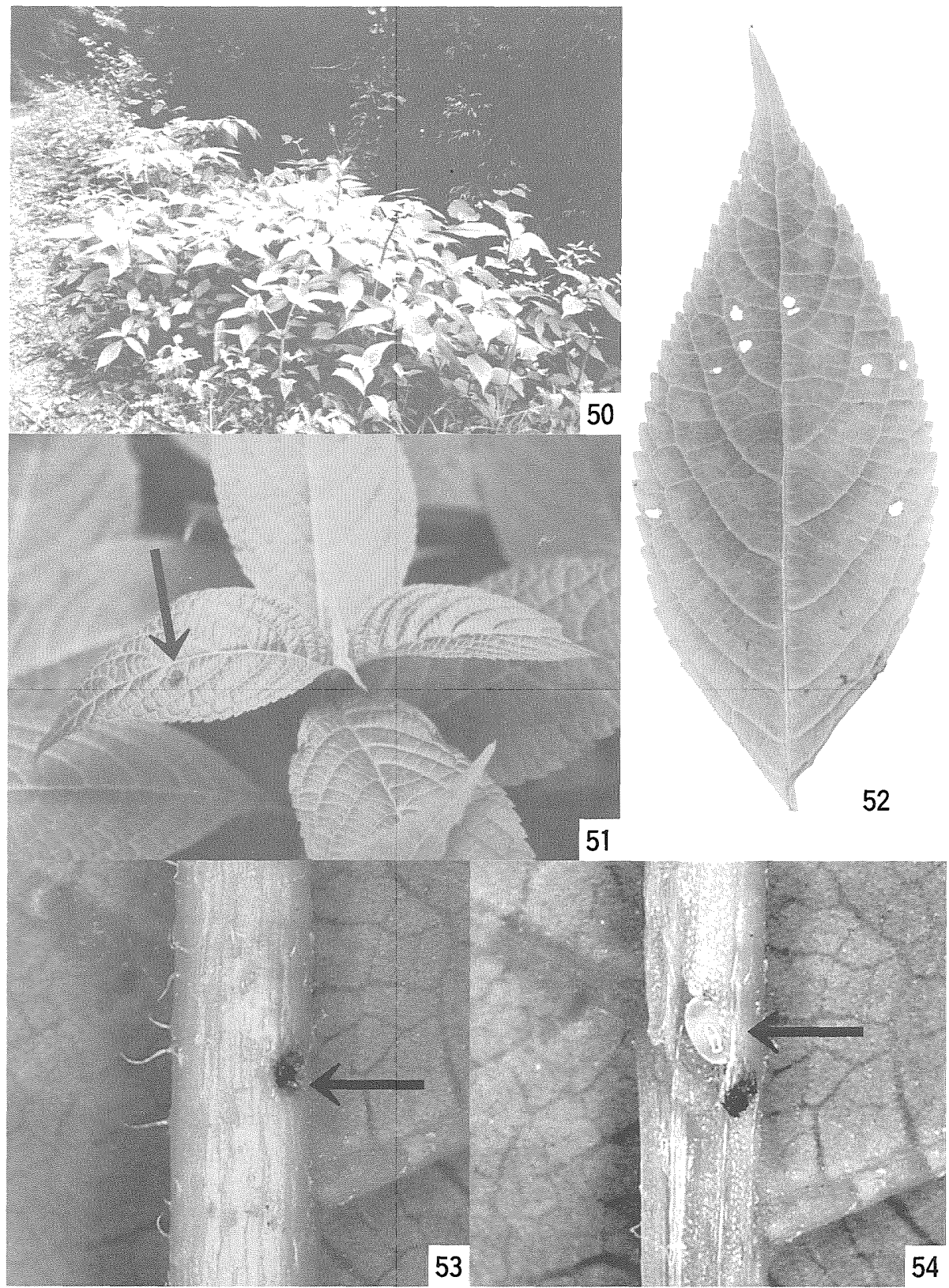

Figs. 50-54. Photographs of Augustinus comes (by Y. Sawada). - 50, A habitat in Sakanotani, Mt. Hyounosen, Tottori Prefecture, West Honshu; 51, Leucosceptrum japonicum (Miq.) Kitamura et Murata and an adult on the leaf (indicated with an arrow); 52 , feeding traces of adults on a leaf; 53, a scar of oviposition (arrow); 54, an egg (arrow). 


\section{Augustinus bouvieri Hustache, 1916}

Cyphosenus bouvieri Hustache, 1916, 120 (type locality: Kumanotaira près Karuizawa). - Morimoto, 1989, 514 (in catalog).

Augustinus bouvieri: Colonnelli, 2004, 74 (in catalog). - Yoshitake et al., 2004, 103 (in checklist).

Diagnosis. This species (Figs. 55, 56) has been considered to be closely related to Augustinus similis (Chûjô) in having the similar general appearance. Also, the affinity between the two species is emphasized by the similar genitalic structures in both sexes (Figs. 59$65,73-75)$, which are observed for the first time in this study. However, A. bouvieri can be distinguished from $A$. similis by the shallower median concavity of male ventrites I and II, the smaller male pygidium, the strong luster and coarse punctures on the female pygidium, and the narrower male aedeagus (Fig. 59).

Redescription. Male. Length of body: 3.27-3.57 mm. Length of rostrum: 1.17-1.23 mm. Maximum width of pronotum: 1.33-1.40 mm. Length of pronotum: 1.13-1.20 mm. Maximum width of elytra: $2.43-2.63 \mathrm{~mm}$. Length of elytra: $2.43-2.63 \mathrm{~mm}$. $\mathrm{N}=5$, for all measurements. Habitus as shown in Figs. 55, 56.

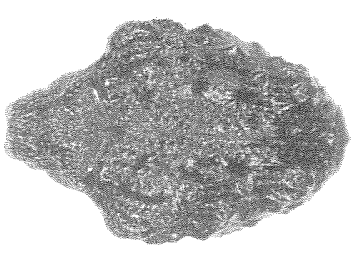

55
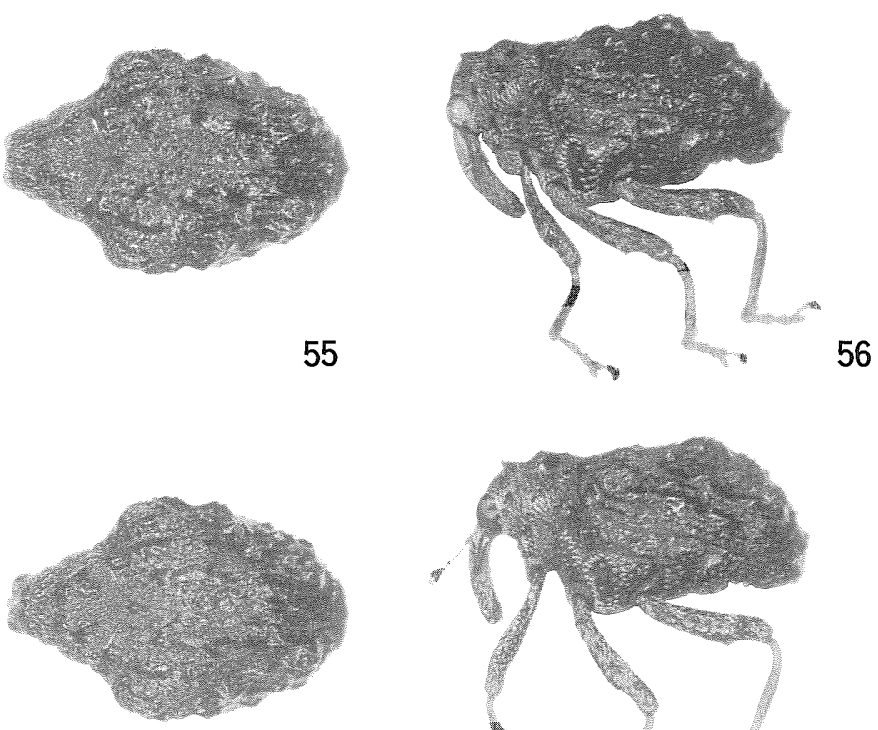

57

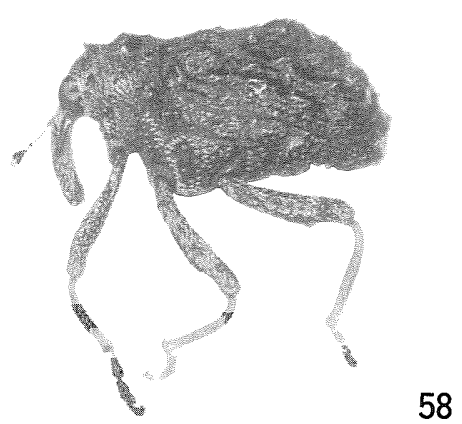

Figs. 55-58. Habitus of Augustinus spp. (the bouvieri-group). - 55, 56, A. bouvieri, male; 57, 58, A. similis, male. 
Forehead weakly depressed. Eyes moderately prominent upwards, not approximated anteriorly. Rostrum robust, 1.00-1.03 times as long as prothorax; dorsum with a slit in median area between antennal insertions; sides strongly expanded apicad. Prothorax 1.14-1.19 times as wide as long; discal prominences smooth, often obtusely 2-peaked, not tuberculate. Elytra 0.99-1.00 times as long as wide, lacking conspicuous postscutellar patch. All femora clavate and dentate. Fore and hind femora evidently toothed. Fore tibiae simple, not dilated outwards at apex. Mid and hind tibiae (Fig. 21) gently curved. Metasternum (Fig. 22) flat, lacking a median projection. Ventrites I and II with a shallower and narrower concavity. Ventrite V with a triangular concavity. Pygidium smaller. Spiculum gastrale (Fig. 64) shorter than aedeagal body and its apodeme taken together, weakly or moderately curved leftwards. Tegmen (Fig. 65) with an apodeme slightly shorter than diameter of tegminal ring. Aedeagal body relatively narrow (Figs. 59,60); apodeme slender, 1.50 times as long as aedeagal body. Endophallus (Fig. 59) longer than aedeagal body and its apodeme taken together, with a pair of plate-like sclerites at base, with a pair of broad sclerites in middle (Fig. 61), and densely with black dentiform sclerites in apical part (Figs. 62, 63); apical sclerites 40-50 in number, often including bi- and tridenticulate ones.

Female. Length of body: $3.23-3.48 \mathrm{~mm}$. Length of rostrum: $1.20-1.30 \mathrm{~mm}$. Maximum width of pronotum: $1.30-1.47 \mathrm{~mm}$. Length of pronotum: $1.10-1.30 \mathrm{~mm}$. Maximum width of elytra: 2.43-2.77 mm. Length of elytra: $2.40-2.60 \mathrm{~mm}$. $\mathrm{N}=5$, for all measurements.

Rostrum 1.00-1.09 times as long as prothorax. Prothorax 1.11-1.29 times as wide as long. Elytra 0.95-1.00 times as long as wide. Pygidium coarsely punctured, strongly shining. Concavity on ventrites I and II shallower and indistinct. Concavity on ventrite V shallower, sparsely covered with scales. Sternite VIII (Fig. 73) with arms nearly $1 / 3$ as long as apodemes. Ovipositor (Fig. 74) with coxites nearly 7.00 times as long as styli; styli shorter, nearly as long as wide. Spermatheca (Fig. 75) with cornu attenuate; collum moderately convex downward.

Specimens examined. $\operatorname{JAPAN}$ : HONSHU. Holotype and 3 paratypes (MNHN). 1 male, Yasugasawa, Sawauchi, Iwate, 31. v. 1998, H. Yoshitake (HY). 1 male, Kasshi-onsen, Fukushima, 12-13. vi. 1994, H. Takizawa (HY). 1 female, Moniwa-rindou, Iizaka, Fukushima, 16. vi. 1981, K. Tazoe (SS). 1 male, Shiobara, Tochigi, 25. v. 1980, H. Katou (HY). Nanma, Kanuma, Tochigi: 1 female, 23. v. 1992, H. Takizawa; 1 female, 1. vi. 1993, H. Takizawa (HY) . 1 male, Kirizumi, Gunma, 27. v. 1989, H. Kojima (ELKU). 1 female, Kameyama, Kimitsu, Chiba, 28. iv. 1985, S. Maru (YS). 1 female, Nippara-Hondani, Okutama, Tokyo, 25. v. 1991, S. Tsuyuki (HY). Mt. Ohyama, Kanagawa: 1 male, 7. v. 1972, H. Takizawa; 1 male, 5. vi. 1977, H. Takizawa; 1 male, 5. v. 1989 (HY). Yabitsu, Tanzawa, Kanagawa: 4 males and 6 females, 30. v. 1983, Y. Shiozaki; 5 males and 8 females, 1. vii. 1983, Y. Shiozaki (YS). 1 female, Yabitsu-Fudakake, Tanzawa, Kanagawa, 25. vii. 1987, A. Yoshida (AY). 1 male, Mikuni-touge, Yamakita, Kanagawa, 23. v. 1994, Y. Notsu (YN). 1 

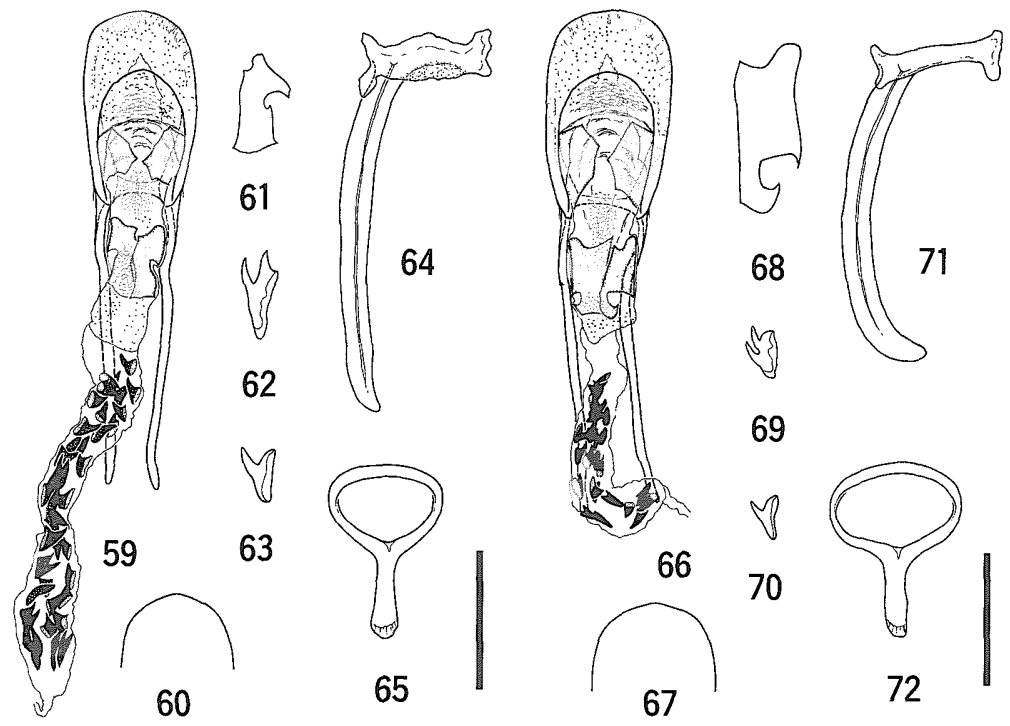

69
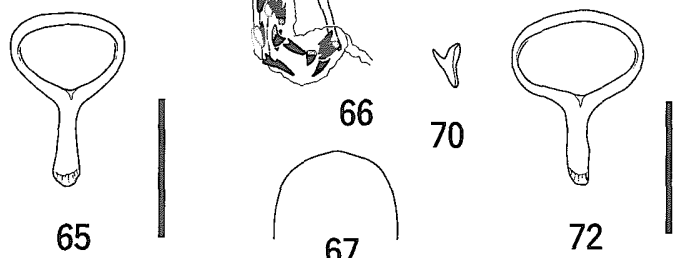

Figs. 59-72. Male genitalia of Augustinus spp. (the bouvieri-group). -59-65, A. bouvieri; 66-72. A. similis; 59, 66, aedeagus, dorsal view, showing endophallic structures; 60, 67, apex of aedeagal body; 61-63, 68-70, endophallic sclerites, enlarged; 64, 71, sternite IX; 65,72 , tegmen. Scale: $0.50 \mathrm{~mm}$, except for $61-63,68-70$.
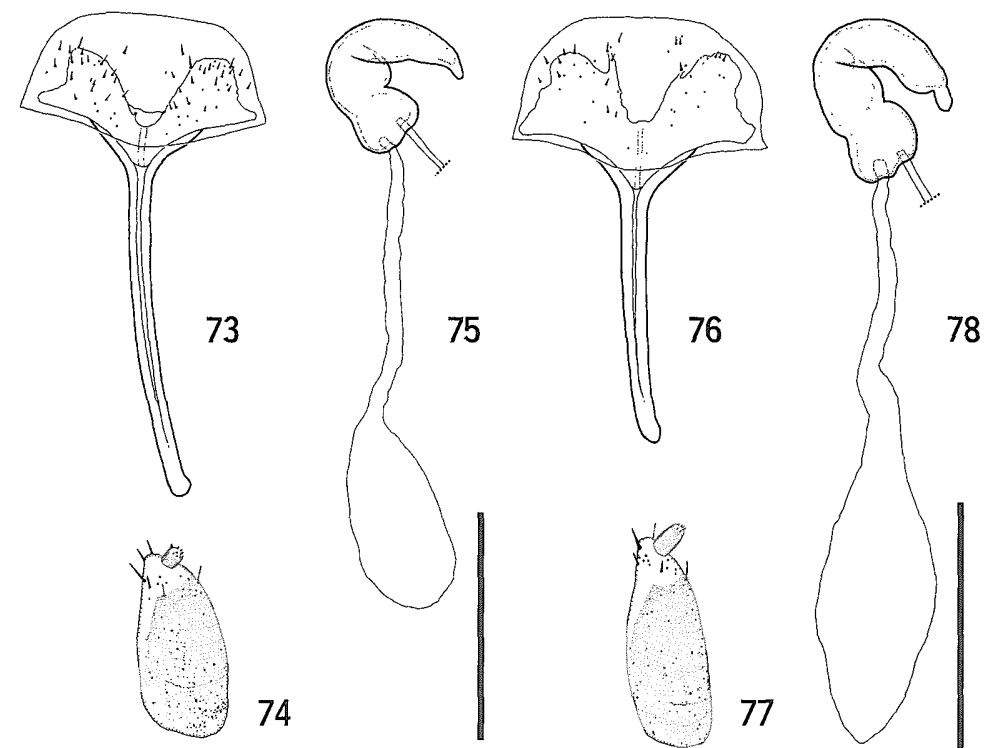

74
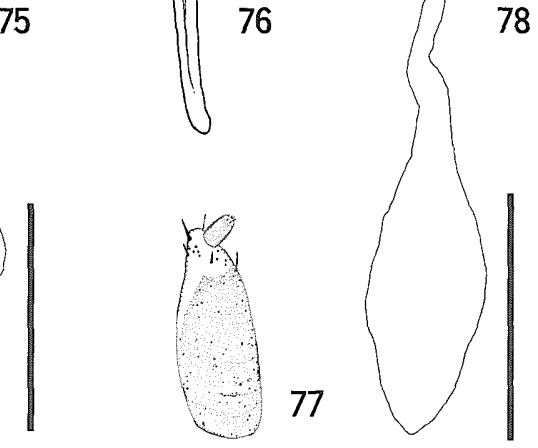

Figs. 73-78. Female genitalia of Augustinus spp. (the bouvieri-group). - 73-75, A. bouvieri; 76-78, A. similis; 73, 76, sternite VIII; 74, 77, ovipositor; 75, 78, spermatheca. Scale: $0.50 \mathrm{~mm}$. 
male and 1 female, Sengokuhara, Hakone, Kanagawa, 8-9. vi. 1996, H. Yoshitake (HY). 1 female, Mt. Daigatake, Hakone, Kanagawa, 23. v. 1999, Y. Notsu (YN). 2 males, Fujiyoshida-rindou, Yamanashi, 5. vi. 1999, Y. Notsu (YN). 1 female, Yamabushi-touge, East Fuji, Yamanashi, 23. vi. 1985, Y. Shiozaki (YS). 2 females, Kajikasawa-rindou, Kajikasawa, Yamanashi, 12. viii. 1999 (HY). 1 male and 1 female, Norogawa-rindou, Minami-Alps, Yamanashi, 5. vi. 1983, Y. Shiozaki (YS). 3 females, Mt. Amagi, Nakaizu, Shizuoka, 3. vi. 1990, H. Kojima (ELKU). 1 male, Miyuki, Mt. Amagi, Amagi-Yugashima, Shizuoka, 16. viii. 1999, T. Shimada (HY). 1 female, Amagi-touge to Nihonsugi-touge, Izu, Shizuoka, 19. vii. 1972, S. Miyakawa (KUM). 1 male, Amagi-kougen, Nakaizu, Shizuoka, 31. v. 1987, S. Miyakawa (KUM). 1 female, Mt. Tohkasa, Izu, Shizuoka, 31. v. 1970, S. Miyakawa (KUM). 2 males, Hacchouike-Kantenbashi, Izu, Shizuoka, 14. v. 1980, J. Okuma (KUM) . 1 male, Mt. Dando, Aichi, 20. vi. 1982, N. Kanie (YS). 1 male, Shirakawa-chou, Gifu, 8. vi. 1990, T. Nohira (TN). 1 female, Kawakami, Sakauchi, Gifu, 6. x. 1982, T. Nohira (TN). 1 female, Sakauchi, Gifu, 4. vi. 1973, M. Sakai (ELEU). 1 male, Yashagaike, Sakauchi, Gifu, 3. vi. 2001, T. Nohira (TN). 2 males, Kunimi, Kasuga, Gifu, 5. v. 1983, T. Nohira (TN). 2 males, Mt. Mikunidake, Kamiishizu, Gifu, 13. v. 2001, T. Nohira (TN). 1 male, Mt. Motaieboshidake, Yamato, Gifu, 4. viii. 2001, T. Nohira (TN).

Distribution. Japan: North to Central Honshu (Fig. 79).

Biological notes. This species inhabits a forest with a wet and open floor and is associated with a shrub of Lamiaceae, Leucosceptrum stellipilum (Miquel) Kitamura et Murata, in a mountainous region of Hakone, Kanagawa Prefecture (M. Horikawa, pers. comm., 2004).

Comments. Augustinus bouvieri shows some geographical variations in the proportion of aedeagal body, the number of endophallic sclerites, and the configuration of spermatheca. Intraspecific relation of this species will be revised when more materials are accumulated from many localities.

\section{Augustinus similis (Chûjô, 1959)}

Cyphosenus similis Chûjô, 1959, 49 (type locality: Mt. Tsurugi-san). - Morimoto, 1984, 315 (habitus as A. bouvieri); 1989, 514 (in checklist).

Augustinus similis: Colonnelli, 1982, 5; 2004, 74 (in catalog). - Yoshitake et al., 2004, 103 (in checklist).

Diagnosis. This species has been considered to be closely related to Augustinus bouvieri (Hustache), but differs from it in the wider and deeper concavity on the disc of basal two ventrites in male, the rounded concavity on male ventrite $V$, the larger male pygidium, the fine punctures and a weaker luster of female pygidium, the wider aedeagal body (Fig. 66), and the shorter endophallus moderately with black dentiform sclerites (Fig. 66). 


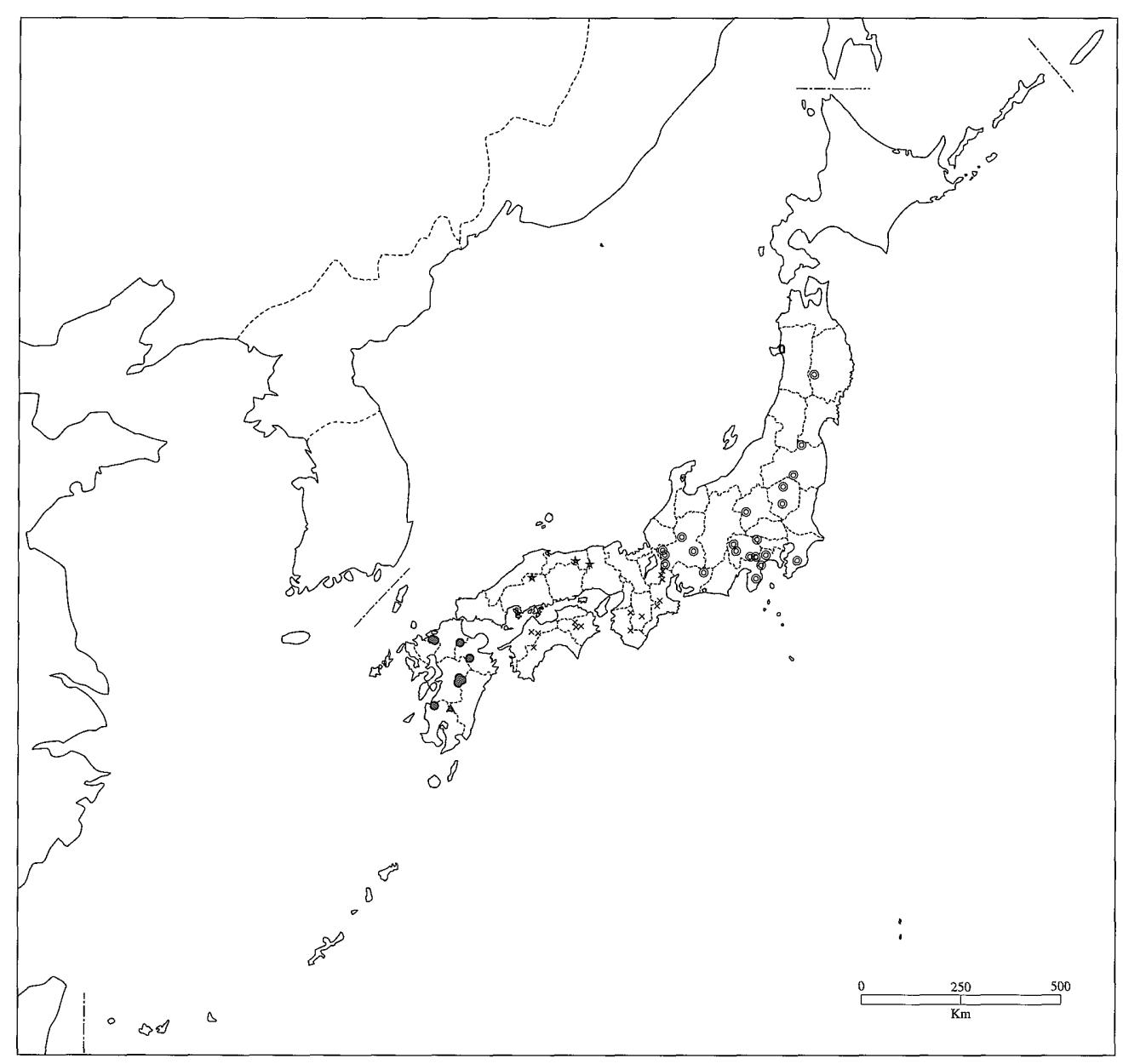

Fig. 79. Geographical distribution of Augustinus in Japan. : A. longipes; : A. comes; (O): A. bouvieri; $\times:$ A. similis; $\mathbf{A}:$ A. sasakii.

Redescription. Male. Length of body: 3.33-3.57 mm. Length of rostrum: 1.17-1.28 mm. Maximum width of pronotum: 1.30-1.47 mm. Length of pronotum: 1.13-1.23 mm. Maximum width of elytra: $2.47-2.67 \mathrm{~mm}$. Length of elytra: $2.50-2.70 \mathrm{~mm} . \mathrm{N}=4$, for all measurements. Habitus as shown in Figs. 57, 58.

Rostrum 1.00-1.04 times as long as prothorax. Prothorax 1.15-1.19 times as wide as long. Elytra 1.00-1.01 times as long as wide. Ventrites I and II with a deeper and wider concavity. Ventrite V with a rounded concavity. Pygidium larger. Spiculum gastrale (Fig. 71) shorter than aedeagal body and its apodeme taken together, moderately curved. Tegmen (Fig. 72) with an apodeme slightly shorter than diameter of tegminal ring. Aedeagal body relatively wide (Figs. 66, 67); apodeme slender, 1.50 times as long as aedeagal body. Endophallus 
(Fig. 66) nearly as long as aedeagal body and its apodeme taken together, with a pair of platelike sclerites at base, with a pair of broad sclerites in middle (Fig. 68), and moderately with black dentiform sclerites in apical part (Fig. 70); apical sclerites 25-30 in number, monodenticulate, often mingled with bi- or tridenticulate ones (Fig. 69). Otherwise practically as in $A$. bouvieri.

Female. Length of body: 3.50-3.73 mm. Length of rostrum: 1.33-1.48 mm. Maximum width of pronotum: $1.43-1.60 \mathrm{~mm}$. Length of pronotum: $1.17-1.38 \mathrm{~mm}$. Maximum width of elytra: $2.53-2.87 \mathrm{~mm}$. Length of elytra: $2.60-2.73 \mathrm{~mm}$. $\mathrm{N}=5$, for all measurements.

Rostrum 1.05-1.14 times as long as prothorax. Prothorax 1.16-1.26 times as wide as long. Elytra 0.95-1.03 times as long as wide. Pygidium finely punctured, more weakly shining. Concavity on ventrites I and II shallower and indistinct. Concavity on ventrite V shallower, sparsely covered with scales. Sternite VIII (Fig. 76) with arms nearly half as long as apodemes; apodemes shorter. Ovipositor (Fig. 77) with coxites nearly 5.00 times as long as styli; styli cylindrical, nearly twice as long as wide. Spermatheca (Fig. 78) with cornu rounded at apex; collum moderately convex.

Specimens examined. JAPAN: HONSHU. Mt. Kouya, Wakayama: 1 male, 10. v. 1995, I. Matoba; 1 female, 6. vii. 1996, H. Hiramatsu (IM). 1 male, Mizukami, Nakahechi, Wakayama, 16. vi. 1994, S. Gotou (IM). 1 male, Mt. Inamuragatake, Nara, 2. vii. 1970, S. Ikebe (IM). Mt. Fujiwara, Mie: 1 male, 1019 m, 8. v. 1955, M. Gotou; 1 male, 15. v. 1957, H. Ichihashi; 1 male, 18. v. 1958, H. Ichihashi; 2 females, 8. vii. 1956, M. Gotou (HI). Mt. Gozaisho, Mie: 1 male, 15. vi. 1961, H. Ichihashi; 1 female, 26. v. 1957, H. Ichihashi; 1 female, 15. viii. 1960, H. Ichihashi (HI) 1 male, Mt. Nonobori, Mie, 14. vi. 1956, H. Ichihashi (HI) 1 male, Yahata, Ichishi-gun, Mie, 30. iv. 1955, H. Ichihashi (HI) . 1 male and 1 female, Hirakura, Misugi, Mie, 27. v. 1995, K. Akita (HY). 1 female, Hirakura, Misugi, Mie, 17. vi. 1995, K. Akita (HY) 3 males and 4 females, Oda, Iina-gun, Mie, 24. vii. 1957, H. Ichihashi (HI) . Mie University Forest, Ichishi-gun, Mie: 1 male, 8. viii. 1956, H. Ichihashi; 1 male, 14. v. 1957, H. Ichihashi (HI) . SHIKOKU. Mt. Tsurugi, Tokushima: 1 female, 1300-1500 m, 3. vi. 1981, H. Takemoto (ELKU); 1 female, 8. viii. 1954, M. Hirai (ELKU); 1 female, Minokoshi-Nishijima Shrine, 1400-1600 m, 15. vii. 1984, S. Hisamatsu (ELEU); 1 male and 1 female, Higashiiyayama, 13. vi. 2004, K. Kume (HY). 2 females, Meotoike, 1450 m, Ichiu, Tokushima, 10. vi. 2004, H. Hirano (HY) 1 female, Mt. Takashiro, Tokushima, 15. vi. 1986, A. Watanabe (YS). Omogokei, Ehime: 1 female, 17. vii. 1950, H. Tanaka; 1 female, 1. viii. 1955, T. Yano; 1 female, 4. vi. 1969, Y. Hori; 1 male, 28. v. 1970, M. Tomokuni; 1 male, 31. v. 1981, S. Hisamatsu; 1 male, 30. viii. 1996, S. Yoshimichi (ELEU). Mt. Saragamine, Ehime: 1 male, 6. v. 1973, A. Oda; 1 female, 1. vii. 1973, A. Oda (ELEU) . 1 female, Tengukougen, Higashitsuno, Kouchi, 16. vii. 1983, A. Ishida (ELKU).

Distribution. Japan: Central Honshu - new record, Shikoku (Fig. 79).

Biological notes. This species occurs in mountainous regions, feeding on a herbaceous 
Lamiaceae, Leucosceptrum japonicum (Miquel) Kitamura et Murata forma barbinerve (Miquel) Kitamura et Murata in Shikoku (Chûjô, 1959) and in Honshu (H. Ichihashi, pers., comm., 2004). According to H. Hirano (pers. comm., 2004), the adults of this species were collected from L. japonicum growing in a wet forest floor around Meotoike Ponds, Tokushima Prefecture, Shikoku.

\section{Augustinus sasakii (Chûjô, 1959)}

Cyphosenus sasakii Chûjô, 1959, 52 (type locality: Mt. Takachiho in range of Mt. Kirishima, Kagoshima Pref.). - Morimoto, 1989, 514 (in checklist).

Augustinus sasakii: Colonnelli, 2004, 74 (in catalog). - Yoshitake et al., 2004, 103 (in checklist).

Diagnosis. According to the detailed original description by Chûjô (1959), Augustinus sasakii is distinctive enough not to be confused with any other congeners from Japan mainly by the following characteristics in male: head lacking paired glabrous spots; forehead very strongly depressed; rostrum slenderer, densely clothed with white robust scales and medially ridged in basal half; discal prominences of prothorax bearing 3 sharp tubercles; elytra with a long postscutellar patch of black scales.

Distribution. Japan: South Kyushu (Fig. 79).

Comments. I could not find the type series, which must be preserved in ELKU.

\section{Discussion}

A total of eleven Augustinus species including the new species described herein are provisionally classified into three species groups, the longipes-, bouvieri-, and sasakii-groups (Appendix 1), based on the results of the present study and previous investigations (Chûjô, 1959; Korotyaev, 1981). The defining characteristics of each group will now be presented.

The longipes-group: forehead weakly depressed; eyes moderately prominent upwards; rostrum (Fig. 1) robust, moderately clothed with brown linear scales on basal half, with a short median slit on dorsum between antennal insertions, not ridged; discal prominences of prothorax (Fig. 4) smooth in both sexes, at most obtusely 2-peaked; elytra without conspicuous scaly patch; mid femora sinuate and edentate (Fig. 19); fore and hind femora minutely toothed in male (Fig. 9); mid and hind tibiae (Figs. 9, 19) bisinuate along internal margin; metasternal receptacle prominent ventrally (Fig. 20); male metasternum with a minute projection at middle of anterior margin (Fig. 20); aedeagal body (Figs. 27, 28, 35, 36) obtusely projected at apex, with a pair of notches near base of each side; endophallus (Figs. 27, 35) very short, bearing approximately 20 black dentiform sclerites; female sternite VIII (Figs. 44, 47) 
very wide, with distantly separated arms; gland of spermatheca (Figs. 46, 49) more or less short, at most as twice as length of spermathecal body.

The bouvieri-group: forehead weakly depressed; eyes moderately prominent upwards; rostrum robust, moderately clothed with brown linear scales on basal half, with a short median slit on dorsum, not ridged; discal prominences of prothorax smooth in both sexes, at most obtusely 2-peaked; elytra without conspicuous scaly patch; all femora clavate and evidently toothed; mid and hind tibiae gently curved, not bisinuate (Fig. 22); metasternum flat in both sexes (Fig. 21); metasternal receptacle simple, lacking projection at middle of anterior margin in both sexes (Fig. 21); aedeagal body rounded at apex, lacking constriction on sides; endophallus (Figs. 59, 66) long, rather densely packed with black sclerites; female sternite VIII (Figs. 73, 76) narrower, with moderately separated arms; gland of spermatheca (Figs. 75,78 ) nearly three times length of spermathecal body.

The sasakii-group: forehead strongly depressed; eyes strongly prominent upwards; rostrum slenderer, densely clothed with white narrow scales and ridged along midline on basal half; discal prominences of prothorax bearing 3 sharp minute tubercles at least in male; elytra with long postscutellar patch of black scales; all femora clavate and evidently toothed; mid tibiae gently curved, not bisinuate; hind tibiae nearly straight; metasternum simple, not projected at middle of anterior margin; metasternal receptacle flat in male, but prominent ventrally in female.

The longipes-group consists of two species, Augustinus longipes (Korotyaev) and A. comes sp. nov., from Southwest Japan. This group resembles the bouvieri-group in having the weakly depressed forehead, the moderately prominent eyes, the robust rostrum with a short median slit, smooth prominences on the pronotum, and non-maculate elytra. However, it differs clearly from the latter group by possessing sinuate and edentate mid femora (Fig. 19), the faint teeth on fore and hind femora (Fig. 9), a bisinuate inner margin of the mid and hind tibiae (Fig. 9), and a prominent metasternal receptacle (Fig. 20). In addition to these features, the longipes-group is characterized by structures of primary and secondary sexual traits in male, such as a median projection on anterior margin of the metasternum, an apical projection of the aedeagal body (Figs. 27, 28, 35, 36), and approximately 20 black sclerites in the shorter endophallus. In female, the metasternum lacks projection at the middle of its anterior margin, the sternite VIII is very wide (Figs. 44, 47), and the gland of spermatheca (Figs. 46, 49) is much shorter than the length of the spermathecal body.

In contrast to the longipes-group, the bouvieri-group has the clavate and evidently toothed femora (Fig. 21), the gently curved mid tibiae (Fig. 21), and the flat metasternum (Fig. 22). Additionally, male weevils of this group share the simple metasternum lacking projection at the middle of its anterior margin (Fig. 22), the aedeagal body rounded at the apex and smooth on the sides, and the long endophallus rather densely packed with black sclerites (Figs. 59, 66). In female, the sternite VIII (Figs. 73, 76) is narrower and the gland of spermatheca 
(Figs. 75, 78) much longer. This group constitutes two Japanese species, Augustinus bouvieri (Hustache) and $A$. similis (Chûjô).

The sasakii-group comprises Augustinus sasakii (Chûjô) and is distinctive enough not to be confused with the former two groups in having the strongly depressed forehead, the strongly prominent eyes, the slenderer rostrum with dense white vestiture and a median ridge on the basal part, the rugged prominences of the prothorax in male, and a long postscutellar patch of the elytra. Judging from the original description, Augustinus horridus (Korotyaev, 1981) from Vietnam may also be a member of this group.

The remaining five Vietnamese species described by Korotyaev (1981) are treated herein as incertae sedis due to the lack of available specimens (Appendix 1). On the basis of their original descriptions are consulted, however, these species may constitute a distinct species group within Augustinus, or possibly a different genus, since they are clearly distinguishable from other congeners by the strongly projected elytra at the bases of intervals V and VI over the basal margin of pronotum and by certain other distinct characteristics.

The present preliminary examination suggests that at least three undescribed species of Augustinus occur in Taiwan. One of these differs remarkably in its external morphology from all other Augustinus species examined. A comprehensive study is needed following the collection of many specimens from various localities in East Asia to construct an intrageneric classification system of this genus.

\section{Key to the Japanese species}

1(2) Rostrum slender, with a median ridge and densely clothed with white robust scales on basal half. Discal prominences denticulate with 2-3 acute tubercles at least in male. (the sasakii-group) Kyushu. A. sasakii (Chûjô)

2(1) Rostrum stout, with a median slit between antennal insertions, moderately clothed with brown linear scales on basal half. Discal prominences obtuse, not denticulate.

3(6) Metasternal receptacle slightly prominent ventrally, with a minute projection at middle of prominence. Mid femora sinuate, lacking tooth. Each side of male aedeagal body with a pair of notches near base. Female sternite VIII very wide, with distantly separated arms. (the longipes-group)

4 (5) Prothorax wider, 1.15-1.24 times as wide as long. Fore tibiae simple, not dilated outwards apically. Male ventrite I moderately punctured in middle. Male aedeagal body robust, slightly bisinuate on sides. Kyushu. A. longipes (Korotyaev)

5 (4) Prothorax narrower, 1.10 times as wide as long. Fore tibiae slightly dilated outwards apically. Male ventrite I densely punctured in middle. Male aedeagal body slenderer, straight on sides. Honshu. A. comes sp. nov.

6(3) Metasternum flat at middle of anterior margin, lacking projection in both sexes. All 
femora clavate, each armed with an evident tooth. Sides of male aedeagal body smooth, not notched near base. Female sternite VIII narrower, with arms closer to each other. (the bouvieri-group)

7(8) Concavity of male ventrites I and II narrower and shallower. Male ventrite V with a triangular concavity. Male pygidium smaller. Female pygidium relatively coarsely punctured, strongly shining. Male. genitalia with narrower aedeagal body and very long endophallus bearing 40-50 black dentiform sclerites. Honshu.

A. bouvieri (Hustache)

8(7) Concavity of male ventrites I and II very deep, wider on II. Male ventrite V with a rounded concavity. Male pygidium larger. Female pygidium finely punctured, weakly shining. Male genitalia with wider aedeagal body and shorter endophallus bearing 2530 black dentiform sclerites. Honshu, Shikoku. A. similis (Chûjô)

\section{Acknowledgments}

I thank Prof. Emeritus J. Yukawa and Prof. O. Tadauchi (ELKU) for their comments and suggestions on the draft of this paper. My thanks are also due to Dr. H. Perrin (MNHN) for giving me an opportunity to study the type material of $A$. bouvieri under her care and to the following persons for the loan or donation of specimens: the late Mr. K. Emoto (Tokyo), Mr. H. Hirano (ELKU), Mr. M. Horikawa (Yokohama), Mr. H. Ichihashi (HI), Dr. H. Kojima (KUM), Mr. K. Kume (Takamatsu), Dr. H. Matsuzawa (formerly Takizawa, Tokyo), Mr. I. Matoba (IM), Mr. T. Nohira (TN), Mr. Y. Notsu (Hiratsuka), Dr. N. Ohbayashi (ELEU), Dr. M. Ôhara (HUM), Mr. S. Saitou (SS), Dr. M. Sakai (ELEU), Dr. Y. Sawada (Koube), Mr. Y. Shiozaki (YS), and Mr. A. Yoshida (AY). I acknowledge Prof. Emeritus K. Morimoto (ELKU) and Dr. E. Colonnelli (Rome) for their constant guidance. This study was supported by a grant from the JSPS Research Fellowships for Young Scientists (No. 14009292).

\section{References}

Alonso-Zarazaga, M. A. \& C. H. C. Lyal, 1999. A World Catalogue of Families and Genera of Curculionoidea (Insecta: Coleoptera). (Excepting Scolytidae and Platypodidae). Entomopraxis, Barcelona.

Chûjô, M., 1959. Descriptions of two new species of the genus Cyphosenus Schultze from Japan (Coleoptera: Curculionidae - Ceuthorrhynchinae). Trans. Shikoku ent. Soc., 6: 4954.

Colonnelli, E., 1982. Sulla posizione sistematica di Cyphosenus Schultze e di Augustinus Korotyaev (Coleoptera, Curculionidae). Doriana, 5: 1-7. 
Colonnelli, E., 2004. Catalogue of Ceutorhynchinae of the World, with a Key to Genera (Insecta: Coleoptera: Curculionidae). Argania editio, Barcelona.

Hustache, A., 1916. Synopsis des Ceuthorrhynchini du Japon. Annls. Soc. ent. Fr., 85: 107144.

Korotyaev, B. A., 1981. New and little known weevils of the subfam. Ceutorhynchinae (Coleoptera, Curculionidae) from the Palaearctic, Indomalayan, and Australian Regions. Ent. Obozr., 50: 126-158. (In Russian.)

Morimoto, K., 1984. Curculionidae. In Hayashi, M., K. Morimoto \& S. Kimoto (eds.), The Coleoptera of Japan in Color, 4: 269-345, pls. 53-68. Hoikusha, Osaka. (In Japanese.)

Morimoto, K., 1989. Curculionoidea. In Hirashima, Y. (superv.), A Checklist of Japanese Insects: 485-538. Entomological Laboratory, Kyushu University, Fukuoka.

Yoshitake, H. \& T. Yamauchi, 2002. A new genus of the Oriental tribe Mecysmoderini (Coleoptera, Curculionidae, Ceutorhynchinae), with descriptions of two new species from Indonesia and Malaysia. Spec. Bull. Jpn. Soc. Coleopterol., Tokyo, (5): 413-423.

Yoshitake, H. \& H. Kojima, K. Morimoto, 2004. Ceutorhynchinae [pp. 100-106]. In Kojima, H. \& K. Morimoto, An online checklist and database of the Japanese weevils (Insecta: Coleoptera: Curculionoidea) (excepting Scolytidae and Platypodidae), Bull. Kyushu Univ. Mus., (2): 33-147. 
Appendix 1. A preliminary classification system of Augustinus.

Augustinus Korotyaev, 1981

The longipes-group

longipes (Korotyaev, 1981)

comes sp. nov.

\section{The bouvieri-group}

bouvieri (Hustache, 1916)

similis (Chûjô, 1959)

The sasakii-group

sasakii (Chûjô, 1959)

horridus (Korotyaev, 1981)

Incertae sedis

aspericollis (Korotyaev, 1981)

intermedius (Korotyaev, 1981)

latus (Korotyaev, 1981)

medvedevi (Korotyaev, 1981)

simplex (Korotyaev, 1981) 